University of Nebraska - Lincoln

DigitalCommons@University of Nebraska - Lincoln

FLAVOR PREFERENCE AND EFFICACY OF VARIABLE DOSE ONTARIO RABIES VACCINE BAIT (ONRAB) DELIVERY IN STRIPED SKUNKS (MEPHITIS MEPHITIS)

\author{
Amy Gilbert \\ USDA APHIS Wildlife Services, amy.t.gilbert@usda.aphis.gov \\ Shylo Johnson \\ USDA APHIS Wildlife Services \\ Nikki Walker \\ USDA APHIS Wildlife Services \\ Alex Beath \\ Artemis Technologies, Inc. \\ Kurt C. Vercauteren \\ USDA APHIS Wildlife Services, kurt.c.vercauteren@usda.gov
}

Follow this and additional works at: https://digitalcommons.unl.edu/icwdm_usdanwrc

Part of the Life Sciences Commons

Gilbert, Amy; Johnson, Shylo; Walker, Nikki; Beath, Alex; and Vercauteren, Kurt C., "FLAVOR PREFERENCE AND EFFICACY OF VARIABLE DOSE ONTARIO RABIES VACCINE BAIT (ONRAB) DELIVERY IN STRIPED SKUNKS (MEPHITIS MEPHITIS)" (2018). USDA Wildlife Services - Staff Publications. 2050.

https://digitalcommons.unl.edu/icwdm_usdanwrc/2050

This Article is brought to you for free and open access by the U.S. Department of Agriculture: Animal and Plant Health Inspection Service at DigitalCommons@University of Nebraska - Lincoln. It has been accepted for inclusion in USDA Wildlife Services - Staff Publications by an authorized administrator of DigitalCommons@University of Nebraska - Lincoln. 


\title{
FLAVOR PREFERENCE AND EFFICACY OF VARIABLE DOSE ONTARIO RABIES VACCINE BAIT (ONRAB) DELIVERY IN STRIPED SKUNKS (MEPHITIS MEPHITIS)
}

\author{
Amy Gilbert, ${ }^{1,3}$ Shylo Johnson, ${ }^{1}$ Nikki Walker, ${ }^{1}$ Alex Beath, ${ }^{2}$ and Kurt VerCauteren ${ }^{1}$ \\ ${ }^{1}$ National Wildlife Research Center, US Department of Agriculture, Animal and Plant Health Inspection Service, Wildlife \\ Services, 4101 Laporte Avenue, Fort Collins, Colorado 80521, USA \\ ${ }_{2}$ Artemis Technologies, Inc., 51 Watson Rd, Guelph, Ontario N1L 1E3, Canada \\ ${ }^{3}$ Corresponding author (email: amy.t.gilbert@usda.aphis.gov)
}

ABSTRACT: In North America, terrestrial wildlife rabies control is achieved by oral rabies vaccination programs that principally target mesocarnivores. Success at rabies control in striped skunks (Mephitis mephitis) has been more limited and may require additional enhancements to existing bait products or novel bait designs and attractants. We evaluated preference among captive striped skunks for six different flavors of placebo Ontario Rabies Vaccine Bait $\left(\mathrm{ONRAB}^{\circledR}\right)$ "Ultralite" Baits (Artemis Technologies, Guelph, Ontario, Canada). Different doses and delivery methods of ONRAB vaccine were tested for efficacy in a subsequent experiment with the same skunks. Cheese-, egg-, and chickenflavored baits were preferred over plain-flavored baits, but a strong preference for a singular flavor was not observed. Vaccine efficacy of $80-100 \%$ was observed among skunks challenged at $335 \mathrm{~d}$ postvaccination across a log range of doses tested by a direct instillation into the oral cavity route, respectively $\left(10^{9.3}-10^{10.2}\right.$ median tissue culture infective doses), in contrast to more-limited efficacy by bait delivery. Our results extended the duration of ONRAB vaccine efficacy in skunks and suggested that there may be limited flexibility to alter vaccine titer and volume in novel bait designs for skunks.

Key words: Bait, ONRAB, rabies, skunk, vaccine.

\section{INTRODUCTION}

Rabies is one of the world's most significant zoonoses, causing an estimated 59,000 cases annually in humans (Hampson et al. 2015). While the overwhelming majority of human rabies deaths are associated with domestic dogs, wildlife also contributes substantially to animal and human exposures in many areas of the world (Christian et al. 2009; Schneider et al. 2009; Monroe et al. 2016). In the US, multiple lineages of rabies virus (RABV) circulating in carnivore wildlife represent spillover from canine rabies cycles while a smaller but significant number of lineages represent spillover from bat rabies cycles (Kuzmin et al. 2012). Control and prevention of RABV circulation in reservoir animal populations is principally achieved by parenteral or oral delivery of vaccines.

The National Rabies Management Program, administered by the US Department of Agriculture (USDA) Animal and Plant Health Inspection Service, Wildlife Services program, has the mission to control and eliminate specific RABV variants circulating in wild mesocarnivores in the US. To manage and control sylvatic RABV, oral rabies vaccination (ORV) is the primary and most costeffective strategy (Rosatte et al. 2007). Disease management strategies, such as ORV, immunize wildlife to create a barrier against RABV transmission by reducing the susceptible fraction of the population. This is accomplished by distribution of vaccine-laden baits across targeted landscapes for consumption by target species (Rosatte et al. 2007).

The RABORAL V-RG ${ }^{\circledR}$ product (Merial, Athens, Georgia, USA) is the only ORV product currently licensed for use with raccoons (Procyon lotor) and coyotes (Canis latrans) in the US and is comprised of a fishmeal attractant matrix coating a sachet containing a live-recombinant vaccinia virus vector expressing an RABV glycoprotein $(\mathrm{G})$ insert. In the US, target wildlife reservoirs include raccoons, gray foxes (Urocyon cinereoargenteus), coyotes, and striped skunks (Mephitis mephitis). While ORV control strategies utilizing V-RG to target wild canids 
in Texas have been successful (Fearneyhough et al. 1998; Sidwa et al. 2005), lower levels of immunity have been observed among raccoon populations from ORV areas, and the current $\mathrm{V}$-RG bait product has not been effective in immunizing captive or free-ranging striped skunks (Grosenbaugh et al. 2007; Slate et al. 2009). As the raccoon is not the sole vector of raccoon RABV variant (Guerra et al. 2003), an effective product to immunize striped skunks is critically needed to ensure long-term ORV program success in eliminating raccoon RABV. A new oral rabies vaccine product has shown promising results for the control of rabies in raccoons and striped skunks in southern Ontario, Canada (Rosatte et al. 2009, 2011). The ONRAB ${ }^{\circledR}$ (Artemis Technologies, Guelph, Ontario, Canada) product is comprised of a sweet attractant matrix coating a blister pack containing a live-recombinant adenovirus vector expressing an RABV G insert (Yarosh et al. 1996). Although direct instillation into the oral cavity (DIOC) of the vaccine constructs used in the V-RG and ONRAB products have proven immunogenic and efficacious against RABV challenge in captive striped skunks (Tolson et al. 1987; Charlton et al. 1992; Grosenbaugh et al. 2007), the efficacy of vaccine delivery by current bait products has only been demonstrated with ONRAB (Brown et al. 2014), and field success of bait delivery to free-ranging striped skunks has only been observed using high-density applications (300 baits $/ \mathrm{km}^{2}$ ) of ONRAB (Rosatte et al. 2011; FehlnerGardiner et al. 2012; Slate et al. 2014). Thus, current bait design, size, and attractants for targeting striped skunks need improvement. Skunks have smaller jaw morphology and likely manipulate baits in a different fashion compared to raccoons (Johnson et al. 2016). To improve delivery of vaccines to skunks, research to investigate shape and flavor preferences and bait manipulation by striped skunks has been ongoing (e.g., Jojola et al. 2007; Johnson et al. 2016). It is necessary to test the efficacy of novel bait products for vaccine delivery, and one potential strategy may involve reduced bait size and vaccine volume for improved oral contact in animals with smaller jaw morphology.

In the past, a variety of bait types and flavors have been used to target skunks. Toxic baits have been used to control skunk populations, but few of these studies have closely investigated bait flavor or type preferences. Most studies focusing on skunk bait preferences are in the context of ORV applications (e.g., Linhart et al. 1997). Nelson and Linder (1972) marked 29\% of skunks with dimethylchlortetracycline using chicken eggs as baits. In a study in Ontario, Canada, baits made from cubes of beef fat were only investigated by two free-ranging skunks (Bachmann et al. 1990), despite observations in an earlier study where captive skunks ate similar baits quite readily (Lawson et al. 1987). When given the choice of egg versus tallow baits, free-ranging skunks showed a higher selectivity for egg baits (Roy and Dorrance 1992). In cafeteria-style trials where baits of various shapes and flavors were offered, captive skunks were observed to preferentially consume meat-flavored baits (Jojola et al. 2007).

We investigated bait interaction and flavor preferences of captive striped skunks with six different flavors of placebo ONRAB "Ultralite" Baits (ULBs). Additionally, the efficacy of varying doses of ONRAB vaccine delivery by DIOC was tested, in comparison to bait delivery with a standard dose, against a lethal RABV challenge.

\section{MATERIALS AND METHODS}

\section{Animals, housing, and restraint}

We obtained 35 naïve adult striped skunks (15 females, 20 males) from Ruby Fur Farm (New Sharon, Iowa, USA). During a 14-d quarantine, we subcutaneously injected sterile passive integrated transponders (PIT) tags (Avid Identification System, Norco, California, USA) under anesthesia for identification (ID). We used 23 skunks for placebo bait flavor-preference trials. Subsequently, 25 skunks were randomly assigned to a vaccine efficacy trial and the remaining 10 skunks were assigned to a virus titration study. Skunks were housed in individual pens $(3 \times 3 \times 2.5$ $\mathrm{m})$, each with an attached den box, in an open-air outdoor building for the bait flavor-preference 
and vaccination phases of the study. Skunks were moved into individual cages $(0.7 \times 1 \times 1 \mathrm{~m})$, with a den box attached, in an Animal Biosafety Level 2 room for challenge and postinfection (PI) monitoring. Skunks were fed a daily ration of $100 \mathrm{~g}$ of Mazuri ${ }^{\circledR}$ omnivore diet (PMI Nutrition International, St. Louis, Missouri, USA) and water was provided ad libitum. Skunks were anesthetized using inhalation delivery of isoflurane gas or an intramuscular injection of a 5:1 ratio of ketamine:xylazine $(10 \mathrm{mg} / \mathrm{kg}$ and $2 \mathrm{mg} / \mathrm{kg}$, respectively) for the purpose of sample collection and inoculation. For isoflurane anesthesia, induction was accomplished by delivery of $5 \%$ isoflurane in oxygen at $5 \mathrm{~L} / \mathrm{min}$ over the den box containing the animal (Bentler et al. 2012), and then animals were transferred to a cone for maintenance at 2 $3 \%$ at $1-2 \mathrm{~L} / \mathrm{min}$ for sample collection, with arousal at ambient conditions following removal of the cone.

\section{Bait flavor-preference trials}

We tested six flavors (chicken, egg, cheese, sweet, fish, and plain) of placebo ONRAB ULBs. Skunks were offered their standard daily ration in the afternoon after completion of the daily morning bait trial. Each possible combination of flavored baits was presented to skunks in metal food bowls as a two-choice test, daily, for $15 \mathrm{~d}$. The sequence of the presentation was randomly determined, and two animals were tested per sequence but with the left and right position of the bait flavors switched (see Supplementary Material Table S1). At the end of a 5-h bait presentation window, all bait remains were removed from individual skunk pens and evaluated. All bait trials were monitored using motionactivated trail cameras (Reconyx Silent Image, Holmen, Wisconsin, USA) and video cameras (Supercircuits model PC161IR, Supercircuits, Inc., Austin, Texas, USA; Zodiac model CAMZ836IR, Zodiac Light Waves Inc., Ontario, Canada; Polaris model EZ-380VF, Polaris USA, Norcross, Georgia, USA). Scores were assigned for each skunk-bait interaction as follows: animal does not approach bait (0); animal approaches bait but does not contact with its mouth (1); oral manipulation of bait by animal but with no puncture of the blister pack (2); oral manipulation and puncture of the blister pack but with incomplete consumption (3); animal consumed entire bait, leaving no trace of remains (4). Camera and video footage were analyzed to verify scores.

\section{Virus titration}

The 92-5A challenge virus is a New York City dog variant of RABV, most recently passaged in red foxes (Vulpes vulpes), and was obtained from the USDA Center for Veterinary Biologics. This virus was selected for study because it met regulatory requirements for purity, potency, and purpose. The neat titer was $10^{7.9}$ median mouse intracerebral lethal doses per milliliter $\left(\right.$ MICLD $_{50} / \mathrm{mL}$ ). Virus was diluted using sterile phosphate-buffered saline supplemented with $2 \%$ fetal bovine serum. Five skunks each were selected to receive a dose of either $10^{6.9}$ or $10^{5.9}$ MICLD $_{50} / \mathrm{mL}$. A baseline blood sample was collected from each skunk immediately prior to intramuscular inoculation with $0.5 \mathrm{~mL}$ of virus into each masseter muscle ( $1.0 \mathrm{~mL}$ total $)$. Animals were monitored daily and, upon display of two or more clinical signs of rabies, skunks were anesthetized with an injection of ketamine:xylazine. Under heavy anesthesia, a terminal blood sample was collected by intracardiac route immediately prior to administration of euthanasia solution (pentobarbital sodium and phenytoin sodium; MWI Veterinary Supply, Boise, Idaho, USA) by the same route. Tissues harvested during necropsy of individual skunks included left and right submandibular salivary glands, brainstem, and cerebellum.

\section{Vaccine immunogenicity and efficacy trial}

After blocking for sex, five skunks each were randomly assigned to one of the five treatment groups. Twenty skunks received sham or live vaccine by DIOC route under light anesthesia, using a plastic catheter assembled to a stopcock, with minimal essential media (MEM) supplemented with $5 \%$ fetal bovine serum (Invitrogen, Carlsbad, California, USA) as a vaccine diluent. With corrections for volume, vaccine doses administered per treatment group were: 0 (MEM only), $10^{10.2}, 10^{9.8}$, or $10^{9.3}$ median tissue culture infective doses $\left(\right.$ TCID $\left._{50}\right)$. Five skunks were offered an egg-flavored live vaccine bait containing $10^{10.2}$ TCID $_{50}$ during an 8-h presentation window. Baseline blood samples were collected prior to vaccination and then postvaccination (PV) on days $30,60,90,180$, and 329. Skunks were challenged with RABV on day 335 PV by intramuscular inoculation with $0.5 \mathrm{~mL}$ of $10^{5.9} \mathrm{MICLD}_{50} / \mathrm{mL}$ into each masseter muscle (1.0 mL total). Animals were monitored until day $75 \mathrm{PI}$, at which point survivors were euthanized. Upon display of two or more clinical signs of rabies, skunks were euthanized. All skunks were sampled postmortem as previously described.

\section{Detection of rabies virus antigen}

Brainstem and cerebellum tissues from individual skunks were submitted to the Veterinary Teaching Hospital Diagnostic Lab at Colorado 
State University, Fort Collins, US, for rabies diagnosis using the direct fluorescent antibody test (Centers for Disease Control and Prevention 2017).

\section{Detection of rabies virus neutralizing antibodies}

Blood samples were centrifuged at $4000 \times \mathrm{G}$ for $15 \mathrm{~min}$, and serum was separated into aliquots using sterile technique. Sera were stored at $-80 \mathrm{C}$ until shipment to the Rabies Laboratory at Kansas State University, Manhattan, KS, US. The sera were processed to titrate the level of rabies virus neutralizing antibodies (rVNA) by standard rapid fluorescent focus inhibition test (Smith et al. 1996), and endpoint titers were converted to international units per milliliter $(\mathrm{IU} / \mathrm{mL})$ by comparison to a positive control standard rabies immune globulin containing 2 $\mathrm{IU} / \mathrm{mL}$. Titers less than $0.1 \mathrm{IU} / \mathrm{mL}$ were considered rVNA negative.

\section{Detection of rabies virus RNA}

Brainstem tissue collected postmortem was analyzed by PCR to confirm a match to the challenge virus. Additionally, paired oral swabs were collected prior to challenge and at day $15 \mathrm{PI}$, day 30 PI, and terminally from challenged skunks. Swabs were stored in MEM and kept on ice packs immediately following collection and within $5 \mathrm{~h}$ were transferred to storage at $-80 \mathrm{C}$ until analysis. We extracted RNA using Trizol reagent (Invitrogen) following the manufacturer's instructions for brain tissue or with minor modifications for swab samples. Swab samples in MEM were vortexed for $15 \mathrm{~s}$ and then $500 \mu \mathrm{L}$ of the solution were removed for extraction with the lysis buffer step included. As a positive control and to determine assay sensitivity, we also extracted the challenge virus. We converted the RNA extracts to cDNA copies by reverse transcription, and partial regions of the RABV G or nucleoprotein $(\mathrm{N})$ genes were targeted for amplification using a SuperScript III One-Step RT-PCR with Platinum Taq kit (Invitrogen). We amplified a 959-base pair (bp) region of the $\mathrm{G}$ gene from rabies-positive brain tissues and the neat challenge inoculum using the onestep RT-PCR kit. A 550-bp region of the $\mathrm{N}$ gene was targeted for the swab samples, but Illustra ${ }^{\mathrm{TM}}$ PuReTaq ${ }^{\mathrm{TM}}$ Ready-To-Go ${ }^{\mathrm{TM}}$ PCR beads (GE Healthcare Bio-Sciences, Pittsburgh, Pennsylvania, USA) were used to amplify a 165-bp product in a hemi-nested PCR. Primers used are listed in Supplementary Material Table S2. The lowest concentration of challenge virus detected was $10^{1.9}$ MICLD $_{50}$, and we used this dilution as a positive control in each round of swab screening. Amplicons produced from swab samples were cleaned using ExoSAP-IT PCR Product Cleanup
Reagent (Affymetrix, Cleveland, Ohio, USA) and sequenced in forward and reverse directions using the respective amplification primers and Big Dye v.3.1 Cycle Sequencing Kit (Applied Biosystems, Foster City, California, USA). Sequencing reactions were purified using Sephadex G-50 Fine (GE Healthcare Bio-Sciences) and then loaded on an ABI 3500xl Genetic Analyzer (Applied Biosystems). Forward and reverse sequences were aligned and visually inspected using Sequencher (Gene Codes Corporation, Ann Arbor, Michigan, USA).

\section{Statistical analyses}

A generalized linear mixed model was used to analyze the bait interaction score data. Bait flavor was treated as a fixed effect, with individual skunk ID and trial day as random effects. A multinomial model with cumulative logit link function was used to model the probability of higher interaction scores in association with bait flavor in SAS v.9.2 (SAS Institute, Cary, North Carolina, USA). Estimated parameter values and standard errors are shown. Odds ratios and 95\% confidence intervals were calculated for pair-wise comparisons of interaction scores across levels of bait flavor. For calculation of group geometric mean rVNA titers, animals with titers less than $0.1 \mathrm{IU} /$ $\mathrm{mL}$ were considered to be $0.05 \mathrm{IU} / \mathrm{mL}$.

\section{RESULTS}

\section{Bait flavor-preference trials}

A total of 690 individual bait trials were conducted, split evenly per bait flavor. The blister packs of baits were punctured during $78 \%$ (538/690) of trials, and both punctured and consumed during $41 \%$ (285/688) of trials (Table 1). The generalized linear mixed model of bait scores demonstrated an effect of bait flavor $\left(F_{5,656}=2.8, P=0.02\right)$ after accounting for variation among individual skunks (skunk $\mathrm{ID}=9.43 \pm 3.4$ ) and trial days (trial day=4.54). Cheese-, chicken-, and egg-flavored baits performed better than did sweet and fish flavors in reference to plain baits (Table 1). Across 488 trials (of 690 bait trials total) where skunk behavior with individual baits could be observed, skunks were documented pinning baits to the ground in $74 \%$ (361/488) of observations, $8 \%(38 / 488)$ held the bait in their mouth with their head in an upright position, less than $1 \%$ (1/488) both pinned and 
TABLE 1. The proportion of trials in which the blister pack was punctured only, or punctured and consumed, and odds ratio of increasing interaction scores by striped skunks (Mephitis mephitis) during a series of two-choice trials evaluating six flavors of placebo ONRAB ${ }^{\circledR}$ "Ultralite” Baits (Artemis Technologies). The plain flavor served as the reference level for comparison of the odds ratios. $-=$ not applicable; $\mathrm{CI}=$ confidence interval.

\begin{tabular}{lccccc}
\hline \multicolumn{1}{c}{ Bait flavor } & $\begin{array}{c}\text { Total no. } \\
\text { of trials }\end{array}$ & $\begin{array}{c}\text { Percent } \\
\text { punctured only }\end{array}$ & $\begin{array}{c}\text { Total no. } \\
\text { of trials }\end{array}$ & $\begin{array}{c}\text { Percent punctured } \\
\text { and consumed }\end{array}$ & $\begin{array}{c}\text { Odds ratio } \\
(95 \% \text { CI })\end{array}$ \\
\hline Cheese & 115 & 81.7 & $114^{\mathrm{a}}$ & 43.9 & $2.6(1.4-4.6)$ \\
Chicken & 115 & 80.0 & 114 & 43.9 & $2.5(1.4-4.5)$ \\
Egg & 115 & 80.9 & 115 & 46.1 & $2.3(1.3-4.2)$ \\
Sweet & 115 & 80.0 & 115 & 39.1 & $1.7(1.0-3.1)$ \\
Fish & 115 & 76.5 & 115 & 37.4 & $1.6(0.9-2.8)$ \\
Plain (reference) & 115 & 68.7 & 115 & 38.3 & - \\
Total & 690 & 78.0 & 688 & 41.4 & - \\
\hline
\end{tabular}

a One trial involving a cheese and chicken bait were treated as missing data, as it could not be determined which bait was completely consumed.

held the bait with their head in an upright position, and in 18\% (88/488) of observations the skunk did not interact with the bait.

\section{Virus titration}

All challenged skunks developed rabies, and sequencing of the brain tissue demonstrated $100 \%$ identity to the challenge virus. Clinical signs most commonly included paresis, ataxia, tremors, and lethargy or irritability. Incubation periods ranged from 10-17 d (median: 12 d) for skunks receiving $10^{6.9}$ MICLD $_{50}$ and 11-22 d (median: $15 \mathrm{~d}$ ) for skunks receiving $10^{5.9}$ MICLD $_{50}$. Between two animals expiring on days 17 and 22, respectively, only one presented a titer of $0.1 \mathrm{IU} / \mathrm{mL}$ on day $15 \mathrm{PI}$, and the same animal had a titer of $0.7 \mathrm{IU} / \mathrm{mL}$ upon expiration on day 22 PI. Nine skunks did not present terminal rVNA titers upon expiration. None of the swab samples collected prior to challenge, or on day 15 PI $(n=2)$, tested positive for RABV RNA. In contrast, terminal swabs collected from eight rabid skunks tested positive for RNA. Of two skunks that tested RNA-negative upon terminal sampling, one was the animal with an rVNA titer. A challenge dose of $10^{5.9} \mathrm{MICLD}_{50}$ was selected for the vaccine efficacy trial.

\section{Vaccine immunogenicity}

Vaccination by DIOC route induced robust rVNA titers in all but a single treated animal, and the quantitative level of induction (i.e., geometric mean titer per treatment group) scaled positively with the vaccine dose received across the treatment groups (Fig. 1). In the group of five skunks which were offered vaccine baits, four skunks ate the baits yet only two seroconverted. One skunk did not interact with the bait during the offering, and rVNA was not detected in this animal at any time point. No sham-treated animals developed rVNA at any prechallenge time point. No adverse reactions to vaccination were noted during the 335-d observation period PV. One skunk was found dead on day 293 PV but tested negative for rabies. This individual skunk had a history of an abscess on its lower mandible which had been previously treated, but an invasive mandibular abscess and an enlarged spleen were the only remarkable findings at necropsy.

\section{Vaccine efficacy}

Five control (sham-vaccinated) skunks developed rabies as did $20 \%$ (1/5) of skunks in the lowest-dose DIOC group and 60\% (3/5) of skunks in the bait delivery group (Table 2). The median incubation period was $12 \mathrm{~d}$ (range: 10-33 d), and sequencing of the brain tissue from rabid skunks demonstrated $100 \%$ identity to the challenge virus. Among the DIOC vaccination groups, survival following lethal challenge was $100 \%$ (4/4), 100\% (5/5), 


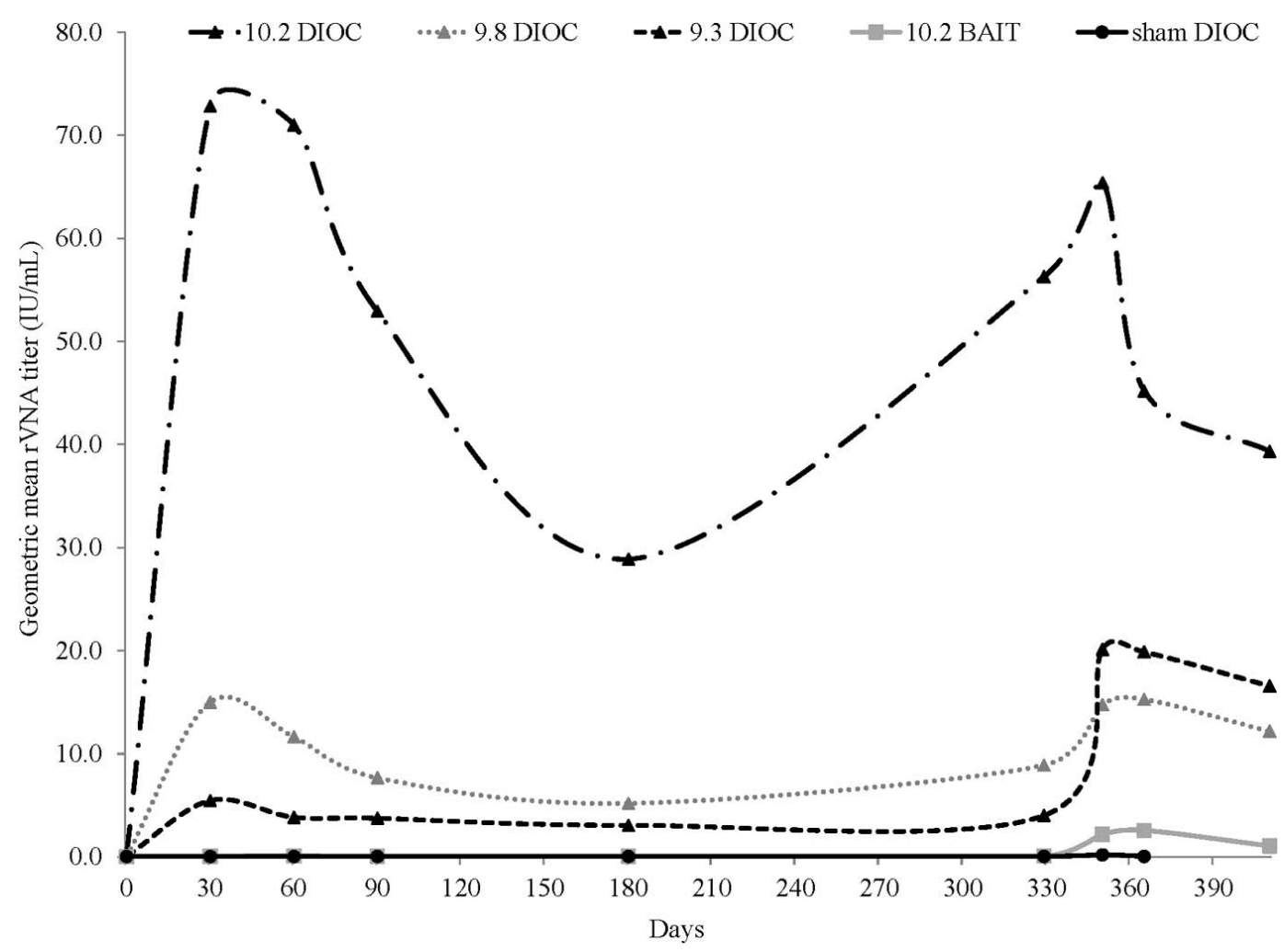

Figure 1. The geometric mean rabies virus neutralizing antibody (rVNA) titers of each treatment group of striped skunks (Mephitis mephitis) vaccinated with ONRAB ${ }^{\circledR}$ (Artemis Technologies) and challenged with rabies virus on day 335 postvaccination. DIOC=direct instillation into the oral cavity; BAIT=bait delivery.

and $80 \%(4 / 5)$, or $93 \%$ (13/14) overall among DIOC treatment groups (Table 2). In the bait group, survival was $40 \%$ (2/5) among skunks offered baits but 50\% (2/4) among skunks that had consumed baits (i.e., one skunk did not interact with a bait during the 8-h presentation).

None of the sham-vaccinated skunks demonstrated rVNA at any time point leading up to challenge (Table 3), but one skunk demonstrated a titer of $3.4 \mathrm{IU} / \mathrm{mL}$ on day 15 PI, immediately prior to expiration on day 16 PI with a titer of $5.0 \mathrm{IU} / \mathrm{mL}$. Two other control skunks, which expired on days 19 and 33 PI, did not demonstrate titers on day 15 PI, and only one had a marginal titer $(0.1 \mathrm{IU} / \mathrm{mL})$ upon expiration. The skunk that did not interact with a bait and a single DIOCvaccinated skunk both succumbed to rabies and did not demonstrate rVNA at any time point nor upon terminal sampling (Table 3).
Between two skunks that consumed baits yet succumbed to challenge, one did not demonstrate rVNA prior to challenge but presented a terminal rVNA titer of $2.2 \mathrm{IU} / \mathrm{mL}$, and the other displayed an rVNA response of $0.2 \mathrm{IU} /$ $\mathrm{mL}$ on day $60 \mathrm{PV}$ only and then presented a titer of $3.1 \mathrm{IU} / \mathrm{mL}$ upon expiration. Conversely, between the two skunks which consumed baits and survived challenge, one did not present an rVNA response until after challenge, and the other demonstrated a consistent but low titer prechallenge (0.2-0.4 IU/ $\mathrm{mL}$ ) and anamnestic response to challenge. The geometric mean titers of each treatment group except the sham-vaccinated animals demonstrated an anamnestic rVNA response at day 15 PI, which declined by day 75 PI (Fig. 1). None of the oral swab samples collected prior to challenge or on day 15 PI $(n=18)$ tested positive for RABV RNA. A single swab sample tested positive on day 30 
TABLE 2. Summary percentages of striped skunks (Mephitis mephitis) that seroconverted and were protected when vaccinated with $\mathrm{ONRAB}^{\circledR}$ (Artemis Technologies) by two delivery routes and challenged with rabies virus 335 d postvaccination. ${ }^{\mathrm{a}}$

\begin{tabular}{|c|c|c|c|c|c|}
\hline Group & $\begin{array}{c}\text { No. } \\
\text { of skunks }\end{array}$ & $\begin{array}{l}\text { Vaccine } \\
\text { route }\end{array}$ & $\begin{array}{l}\text { Vaccine dose } \\
\left(\log \text { TCID }_{50}\right)\end{array}$ & $\begin{array}{c}\text { Percent } \\
\text { seroconverted }^{\mathrm{b}}\end{array}$ & $\begin{array}{l}\text { Percent surviving } \\
\text { rabies challenge }^{\mathrm{c}}\end{array}$ \\
\hline A & 5 & DIOC & 10.2 & 100 & 100 \\
\hline B & 5 & DIOC & 9.8 & 100 & 100 \\
\hline $\mathrm{C}$ & 5 & DIOC & 9.3 & 80 & 80 \\
\hline $\mathrm{D}$ & 5 & BAIT & 10.2 & 40 & 40 \\
\hline $\mathrm{E}$ & 5 & DIOC & Sham & 0 & 0 \\
\hline
\end{tabular}

${ }^{\mathrm{a}} \mathrm{TCID}_{50}=$ median tissue culture infective doses; DIOC $=$ direct instillation into the oral cavity; BAIT $=$ bait delivery.

${ }^{\mathrm{b}}$ Percent of animals in group with a level of rabies virus neutralizing antibody greater than or equal to $0.2 \mathrm{IU} / \mathrm{mL}$ at any time point prior to challenge.

${ }^{c}$ Percent surviving to $75 \mathrm{~d}$ postinfection.

PI from a skunk that developed rabies and expired on day 33 PI. Among terminal swabs from nine rabid skunks, six tested RNApositive. The three terminal swabs from rabid skunks that tested RNA-negative were from skunks with terminal titers of 2.2, 3.1, and 5.0 $\mathrm{IU} / \mathrm{mL}$. All terminal swabs from 15 skunks surviving to day 75 PI tested negative for RNA.

\section{DISCUSSION}

Skunks are omnivores and consume a wide variety of prey and forage items. The placebobait interaction trials revealed a preference for cheese, chicken, and egg flavors when compared to plain baits, but strong preference for a single flavor was not observed. Similar consumption rates were observed for ULB and spherical baits in comparing the results of this study with a similar study utilizing the same cohort of captive skunks and over a standardized presentation period (Johnson et al. 2016), suggesting a lack of shape preference between oblong and spherical bait presentations. Many factors can influence what makes a bait effective at targeting skunks. Nevertheless, factors such as season, host density, habitat use, and nontarget species competition also affect application strategy on the landscape and subsequent uptake rates by free-ranging target animals. Thus, field testing of flavor candidates identified in the captive study will be important.
High resistance to challenge was observed in skunks vaccinated by the DIOC route. One early study reported $100 \%$ (8/8) survival of skunks vaccinated via DIOC with $10^{8.1}$ TCID $_{50}$ of a precursor to the ONRAB vaccine compared to $100 \%$ (8/8) mortality of control animals when challenged 90 days PV (Charlton et al. 1992). A later study observed $100 \%$ (23/23) survival of skunks vaccinated via DIOC with $10^{10.3}$ TCID $_{50}$ of commercial ONRAB (AdRG1.3) vaccine, 81\% (25/31) survival of animals consuming a ULB containing $10^{10.3}$ TCID $_{50}$ of commercial ONRAB, and $100 \%$ (10/10) mortality of control animals when challenged $247 \mathrm{~d}$ PV (Brown et al. 2014). This study further confirms and extends the immunogenicity and efficacy of ONRAB vaccine by a DIOC route in skunks challenged $335 \mathrm{~d}$ PV. At vaccine doses of $10^{9.8}$ and $10^{10.2}$ TCID $_{50}$ by DIOC, $100 \%$ (9/9) survival was observed, with slightly lower survival in the $10^{9.3}$ TCID $_{50}$ group. Despite the low sample sizes in this study, similar efficacy was observed with DIOC doses that were approximately one log lower than the bait doses used in Brown et al. (2014). It has been suggested that the vaccine dose for bait delivery should be approximately one log higher than the lowest dose efficacious by DIOC route (World Organisation for Animal Health 2016). Observations in this and earlier studies suggest that there may not be substantial flexibility to lower the current vaccine dose (about $10^{10} \mathrm{TCID}_{50}$ ) of ONRAB for bait 
TABLE 3. Rabies virus neutralizing antibody (rVNA) titers for individual striped skunks (Mephitis mephitis) vaccinated with $\mathrm{ONRAB}^{\circledR}$ (Artemis Technologies), and their fate following infection with rabies virus. ${ }^{a}$

\begin{tabular}{|c|c|c|c|c|c|c|c|c|c|c|c|c|c|c|}
\hline \multirow[b]{2}{*}{$\begin{array}{l}\text { Skunk } \\
\text { ID }\end{array}$} & \multirow[b]{2}{*}{ Sex } & \multirow[b]{2}{*}{$\begin{array}{l}\text { Vaccine } \\
\text { route }\end{array}$} & \multirow{2}{*}{$\begin{array}{c}\text { Vaccine } \\
\text { dose } \\
(\log \\
\left.\text { TCID }_{50}\right)\end{array}$} & \multicolumn{10}{|c|}{$\mathrm{rVNA}(\mathrm{IU} / \mathrm{mL})$} & \multirow{2}{*}{$\begin{array}{c}\text { Fate } \\
\text { (incubation } \\
\text { period, } \\
\text { days) }\end{array}$} \\
\hline & & & & $\begin{array}{c}\text { Day } \\
0\end{array}$ & $\begin{array}{c}\text { Day } \\
30\end{array}$ & $\begin{array}{c}\text { Day } \\
60\end{array}$ & $\begin{array}{c}\text { Day } \\
90\end{array}$ & $\begin{array}{l}\text { Day } \\
180\end{array}$ & $\begin{array}{l}\text { Day } \\
329\end{array}$ & $\begin{array}{l}\text { Day } \\
350^{\mathrm{b}}\end{array}$ & $\begin{array}{l}\text { Day } \\
365\end{array}$ & $\begin{array}{l}\text { Day } \\
410\end{array}$ & Terminal $^{\mathrm{c}}$ & \\
\hline $1-279$ & $\mathrm{~F}$ & DIOC & 10.2 & $<0.1$ & 31.0 & 34.0 & 22.0 & 13.7 & 11.0 & 27.5 & 22.0 & 18.5 & & S \\
\hline $6-614$ & $\mathrm{~F}$ & DIOC & 10.2 & $<0.1$ & 131.0 & 149.0 & 120.0 & 90.0 & 250 & 180 & 80.0 & 70.0 & & S \\
\hline $8-821$ & $\mathrm{~F}$ & DIOC & 10.2 & $<0.1$ & 111.0 & 31.0 & 34.0 & 13.0 & - & - & - & - & n.d. & $\mathrm{N}^{\mathrm{e}}$ \\
\hline 3-076 & M & DIOC & 10.2 & $<0.1$ & 77.0 & 149.0 & 149.0 & 38.0 & 67.5 & 60.0 & 42.0 & 68.5 & & S \\
\hline 6-881 & M & DIOC & 10.2 & $<0.1$ & 59.0 & 77.0 & 31.0 & 33.0 & 54.0 & 61.5 & 56.5 & 27.0 & & S \\
\hline 3-882 & $\mathrm{F}$ & DIOC & 9.8 & $<0.1$ & 53.0 & 53.0 & 45.0 & 33.0 & 60.0 & 67.5 & 54.0 & 47.0 & & S \\
\hline 3-271 & $\mathrm{F}$ & DIOC & 9.8 & $<0.1$ & 30.0 & 20.0 & 7.0 & 5.4 & 11.5 & 24.0 & 22.0 & 17.5 & & S \\
\hline $7-065$ & M & DIOC & 9.8 & $<0.1$ & 0.5 & 0.9 & 0.6 & 0.2 & 0.4 & 4.8 & 4.4 & 2.5 & & S \\
\hline $5-839$ & M & DIOC & 9.8 & $<0.1$ & 34.0 & 28.0 & 31.0 & 31.0 & 36.5 & 10.0 & 29.5 & 29.5 & & S \\
\hline $6-609$ & M & DIOC & 9.8 & $<0.1$ & 28.0 & 8.0 & 4.5 & 3.4 & 5.5 & 9.0 & 5.4 & 4.4 & & S \\
\hline $1-822$ & $\mathrm{~F}$ & DIOC & 9.3 & $<0.1$ & 12.5 & 6.9 & 8.6 & 11.3 & 9.2 & 27.5 & 16.0 & 13.7 & & S \\
\hline $7-879$ & $\mathrm{~F}$ & DIOC & 9.3 & $<0.1$ & $<0.1$ & $<0.1$ & $<0.1$ & $<0.1$ & $<0.1$ & - & - & - & $<0.1$ & D (12) \\
\hline $1-041$ & M & DIOC & 9.3 & $<0.1$ & 31.0 & 20.0 & 26.0 & 13.0 & 14.0 & 31.5 & 27.0 & 17.5 & & S \\
\hline $8-120$ & M & DIOC & 9.3 & $<0.1$ & 20.0 & 12.0 & 8.6 & 7.4 & 11.5 & 14.0 & 18.5 & 17.0 & & S \\
\hline $8-593$ & M & DIOC & 9.3 & $<0.1$ & 12.5 & 10.0 & 7.6 & 5.0 & 14.0 & 13.5 & 19.5 & 18.5 & & S \\
\hline 5-013 & $\mathrm{F}$ & DIOC & Sham & $<0.1$ & $<0.1$ & $<0.1$ & $<0.1$ & $<0.1$ & $<0.1$ & $<0.1$ & $<0.1$ & - & 0.1 & $\mathrm{D}(33)$ \\
\hline $2-380$ & $\mathrm{~F}$ & DIOC & Sham & $<0.1$ & $<0.1$ & $<0.1$ & $<0.1$ & $<0.1$ & $<0.1$ & - & - & - & n.d. & $\mathrm{D}(11)$ \\
\hline $5-591$ & M & DIOC & Sham & $<0.1$ & $<0.1$ & $<0.1$ & $<0.1$ & $<0.1$ & $<0.1$ & - & - & - & $<0.1$ & $\mathrm{D}(10)$ \\
\hline 9-119 & M & DIOC & Sham & $<0.1$ & $<0.1$ & $<0.1$ & $<0.1$ & $<0.1$ & $<0.1$ & $<0.1$ & - & - & $<0.1$ & D (19) \\
\hline $3-589$ & M & DIOC & Sham & $<0.1$ & $<0.1$ & $<0.1$ & $<0.1$ & $<0.1$ & $<0.1$ & 3.4 & - & - & 5.0 & $\mathrm{D}(16)$ \\
\hline $8-827^{\mathrm{f}}$ & $\mathrm{F}$ & BAIT & 10.2 & $<0.1$ & $<0.1$ & $<0.1$ & $<0.1$ & $<0.1$ & $<0.1$ & - & - & - & $<0.1$ & $\mathrm{D}(11)$ \\
\hline $7-857$ & $\mathrm{M}$ & BAIT & 10.2 & $<0.1$ & $<0.1$ & $<0.1$ & $<0.1$ & $<0.1$ & $<0.1$ & 0.2 & 0.3 & 0.1 & & S \\
\hline $6-856$ & $\mathrm{M}$ & BAIT & 10.2 & $<0.1$ & 0.3 & 0.2 & 0.2 & 0.2 & 0.4 & 24.0 & 22.0 & 11.3 & & S \\
\hline $1-261$ & $\mathrm{M}$ & BAIT & 10.2 & $<0.1$ & $<0.1$ & $<0.1$ & $<0.1$ & $<0.1$ & $<0.1$ & - & - & - & 2.2 & $\mathrm{D}(10)$ \\
\hline $2-337$ & $\mathrm{M}$ & BAIT & 10.2 & $<0.1$ & $<0.1$ & 0.2 & $<0.1$ & $<0.1$ & $<0.1$ & - & - & - & 3.1 & $\mathrm{D}(12)$ \\
\hline
\end{tabular}

${ }^{a} \operatorname{TCID}_{50}=$ median tissue culture infective doses; $\mathrm{F}=$ female; $\mathrm{M}=$ male; $\mathrm{DIOC}=$ direct instillation into the oral cavity; BAIT $=$ bait delivery; n.d. $=$ not determined.

${ }^{\mathrm{b}}$ Time point is day 15 postinfection.

${ }^{\mathrm{c}}$ Terminal titers for animals surviving to day 75 postinfection are listed under day 410 .

${ }^{\mathrm{d}} \mathrm{S}=$ survived to day 75 postinfection and tested rabies negative; $\mathrm{N}=$ nonspecific death prior to challenge and tested rabies negative; $\mathrm{D}=$ succumbed and tested rabies positive.

e This animal was found dead on day 293 postvaccination.

${ }^{\mathrm{f}}$ Animal did not interact with the bait during offering period.

presentation. Greater sample sizes are needed for robust determination of the minimum protective dose of ONRAB by DIOC route in striped skunks.

In contrast to Brown et al. (2014), we observed low efficacy by bait delivery. In both studies, the titers of vaccine used in the baits and subsequent doses delivered were similar. In Brown et al. (2014), 93\% (28/30) of skunks entirely or mostly consumed the blister packs of baits whereas the remaining 7\% (2/30) presented some evidence of blister pack chewing. In this study, 60\% (3/5) of skunks entirely or mostly consumed the blister packs of baits whereas $20 \%$ (1/5) presented some evidence of blister pack chewing and 20\% (1/ 5) did not interact at all with the bait. Seasonal differences may have been a factor in the reduced level of interaction observed among skunks in the current study (i.e., bait offering 
in July versus October in the prior study). The 8-h offering period used in this study appears adequate, based on observations in Brown et al. (2014) where all skunks had consumed or interacted with baits within $1.5 \mathrm{~h}$. In the Brown et al. (2014) study, food was withheld from animals for $24 \mathrm{~h}$ prior to the bait presentation whereas in this study food was withheld from animals for about $18 \mathrm{~h}$ prior to the bait presentation, yet the animals in our study had likely consumed their daily ration on the previous day. A slightly lower proportion of skunks that consumed baits seroconverted with rabies antibodies in the current study, although most antibody measurements were not directly comparable due to the different test methodology used and low power for comparison in the current study. Subsequent laboratory evaluations of the eggflavored matrix used in this study revealed virucidal properties of the formulation, which may have interfered with the immunogenicity and efficacy of the vaccine bait used in this study. When coupled with a longer interval between vaccination and challenge, these factors may potentially explain the lower bait efficacy observed in this study. Furthermore, the serologic response data of the skunks vaccinated by bait were inconsistent with the efficacy results in this study, where vaccination responders and nonresponders both succumbed and survived respectively, yet the phenomenon is not unique to this dataset (Moore et al. 2017).

Skunks continue to present challenges for ORV programs. In the context of US ORV objectives, vaccination of skunk populations may be necessary to achieve elimination of raccoon RABV, given levels of spillover into this key secondary host (Guerra et al. 2003; Wallace et al. 2014). It seems unlikely that the dose of vaccine used in ONRAB baits for skunks can be reduced substantially. However, slight reductions in the volume of vaccine carried by the blister packs, which do not compromise vaccine dose, may still be one strategy for consideration in an attempt to alter the manipulation behavior of skunks for improved contact of the vaccine with the oral mucosa. Nevertheless, field testing of modi- fied bait designs is still critical to evaluate the success in uptake and immune induction by free-ranging skunks.

\section{ACKNOWLEDGMENTS}

The animal studies were approved by the National Wildlife Research Center Institutional Animal Care and Use Committee under protocols 2142 and 2258, and import and housing of skunks were permitted under Colorado Parks and Wildlife 13TR2056A1, 14TR2056, and 15TR2143. The vaccine importation was authorized by the USDA Center for Veterinary Biologics permit VB-139842. The authors thank Scott Bentham for contributions to the study design and the following persons for invaluable technical assistance: T. Rigg, S. Eaton, J. Kanine, C. Wickham, D. Wostenberg, B. Schmit, D. Kohler, C. Ellis, and the Animal Care Unit at the National Wildlife Research Center, Fort Collins. The study was funded by the USDA National Rabies Management Program. The findings and conclusions of the report are those of the authors and do not necessarily represent the official position of their respective institutions or funding source.

\section{SUPPLEMENTARY MATERIAL}

Supplementary material for this article is online at http://dx.doi.org/10.7589/2017-04-073.

\section{LITERATURE CITED}

Bachmann P, Bramwell RN, Fraser SJ, Gilmore DA, Johnston DH, Lawson KF, MacInnes CD, Matejka FO, Miles HE, Pedde MA, et al. 1990. Wild carnivore acceptance of baits for delivery of liquid rabies vaccine. J Wildl Dis 26:486-501.

Bentler KT, Gossett DN, Root JJ. 2012. A novel isoflurane anesthesia induction system for raccoons. Wildl Soc Bull 36:807-812.

Brown LJ, Rosatte RC, Fehlner-Gardiner C, Ellison JA, Jackson FR, Bachmann P, Taylor JS, Franka R, Donovan D. 2014. Oral vaccination and protection of striped skunks (Mephitis mephitis) against rabies using ONRAB ${ }^{\circledR}$. Vaccine 32:3675-3679.

Centers for Disease Control and Prevention. 2017. Protocol for postmortem diagnosis of rabies in animals by direct fluorescent antibody testing. https://www.cdc.gov/rabies/pdf/RabiesDFASPv2.pdf. Accessed September 2017.

Charlton KM, Artois M, Prevec L, Campbell JB, Casey GA, Wandeler AI, Armstrong J. 1992. Oral rabies vaccination of skunks and foxes with a recombinant human adenovirus vaccine. Arch Virol 123:169-179. 
Christian KA, Blanton JD, Auslander M, Rupprecht CE. 2009. Epidemiology of rabies post-exposure prophylaxis-United States of America, 2006-2008. Vaccine 27:7156-7161.

Fearneyhough MG, Wilson PJ, Clark KA, Smith DR, Johnston DH, Hicks BN, Moore GM. 1998. Results of an oral rabies vaccination program for coyotes. $J$ Am Vet Med Assoc 212:498-502.

Fehlner-Gardiner C, Rudd R, Donovan D, Slate D, Kempf L, Badcock J. 2012. Comparing ONRAB ${ }^{\circledR}$ and RABORAL V-RG ${ }^{\circledR}$ oral rabies vaccine field performance in raccoons and striped skunks, New Brunswick, Canada, and Maine, USA. J Wildl Dis 48:157167.

Grosenbaugh DA, Maki JL, Rupprecht CE, Wall DK. 2007. Rabies challenge of captive striped skunks (Mephitis mephitis) following oral administration of a live vaccinia-vectored rabies vaccine. $J$ Wildl Dis 43: 124-128.

Guerra MA, Curns AT, Rupprecht CE, Hanlon CA, Krebs JW, Childs JE. 2003. Skunk and raccoon rabies in the eastern United States: Temporal and spatial analysis. Emerg Infect Dis 9:1143-1150.

Hampson K, Coudeville L, Lembo T, Sambo M, Kieffer A, Attlan M, Barrat J, Blanton JD, Briggs DJ, Cleaveland S, et al. 2015. Estimating the global burden of endemic canine rabies. PLoS Negl Trop Dis 9:e0003709.

Johnson SR, Crider NJ, Weyer GA, Tosh RD, VerCauteren KC. 2016. Bait development for oral delivery of pharmaceuticals to raccoons (Procyon lotor) and skunks (Mephitis mephitis). J Wildl Dis 52:893-901.

Jojola SM, Robinson SJ, VerCauteren KC. 2007. Oral rabies vaccine (ORV) bait uptake by captive striped skunks. J Wildl Dis 43:97-106.

Kuzmin IV, Shi M, Orciari LA, Yager PA, Velasco-Villa A, Kuzmina NA, Streicker DG, Bergman DL, Rupprecht CE. 2012. Molecular inferences suggest multiple host shifts of rabies viruses from bats to mesocarnivores in Arizona during 2001-2009. PLoS Pathog 8:e1002786.

Lawson KF, Black JG, Charlton KM, Johnston DH, Rhodes AJ. 1987. Safety and immunogenicity of a vaccine bait containing ERA strain of attenuated rabies virus. Can J Vet Res 51:460-464.

Linhart SB, Kappeler A, Windberg LA. 1997. A review of baits and bait delivery systems for free-ranging carnivores and ungulates. Contraception in wildlife. Technical Bulletin 1853. Animal and Plant Health Inspection Service, US Department of Agriculture, Washington, DC, pp. 69-132.

Monroe BP, Yager P, Blanton J, Birhane MG, Wadhwa A, Orciari L, Petersen B, Wallace R. 2016. Rabies surveillance in the United States during 2014. J Am Vet Med Assoc 248:777-788.

Moore SM, Gilbert A, Vos A, Freuling CM, Ellis C, Kliemt J, Müller T. 2017. Rabies virus antibodies from oral vaccination as a correlate of protection against lethal infection in wildlife. Trop Med Infect Dis 2:31-55.

Nelson RL, Linder RL. 1972. Percentage of raccoons and skunks reached by egg baits. J Wildl Manage 36: 1327-1329.

Rosatte RC, Donovan D, Davies JC, Allan M, Bachmann P, Stevenson B, Sobey K, Brown L, Silver A, Bennett K, et al. 2009. Aerial distribution of $\mathrm{ONRAB}^{\circledR}$ baits as a tactic to control rabies in raccoons and striped skunks in Ontario, Canada. J Wildl Dis 45:363-374.

Rosatte RC, Donovan D, Davies JC, Brown L, Allan M, Von Zuben V, Bachmann P, Sobey K, Silver A, Bennett K, et al. 2011. High-density baiting with $\mathrm{ONRAB}^{\circledR}$ rabies vaccine baits to control Arcticvariant rabies in striped skunks in Ontario, Canada. $J$ Wildl Dis 47:459-465.

Rosatte RC, Tinline RR, Johnston DH. 2007. Rabies control in wild carnivores. In: Rabies, 2nd Ed., Jackson AC, Wunner WH, editors. Academic Press, San Diego, California, pp. 595-634.

Roy LD, Dorrance MJ. 1992. Efficacy and selectivity of eggs and tallow baits for skunk control. Wildl Soc Bull 20:326-330.

Schneider MC, Romijn PC, Uieda W, Tamayo H, Da Silva DF, Belotto A, Da Silva JB, Leanes LF. 2009. Rabies transmitted by vampire bats to humans: An emerging zoonotic disease in Latin America? Rev Panam Salud Publ 25:260-269.

Sidwa TJ, Wilson PJ, Moore GM, Oertli EH, Hicks BN, Rohde RE, Johnston DH. 2005. Evaluation of oral rabies vaccination programs for control of rabies epizootics in coyotes and gray foxes: 1995-2003. J Am Vet Med Assoc 227:785-792.

Slate D, Algeo TP, Nelson KM, Chipman RB, Donovan D, Blanton JD, Niezgoda M, Rupprecht CE. 2009. Oral rabies vaccination in North America: Opportunities, complexities, and challenges. PLoS Negl Trop Dis 3:e549.

Slate D, Chipman RB, Algeo TP, Mills SA, Nelson KM, Croson CK, Dubovi EJ, Vercauteren K, Renshaw RW, Atwood T, et al. 2014. Safety and immunogenicity of Ontario rabies vaccine bait (ONRAB) in the first US field trial in raccoons (Procyon lotor). J Wildl Dis 50:582-595.

Smith JS, Yager P, Baer G. 1996. A rapid fluorescent focus inhibition test (RFFIT) for determining rabies virusneutralizing antibody. In: Laboratory techniques in rabies, Meslin FX, Kaplan MM, Koprowski H, editors. World Health Organization, Geneva, Switzerland, pp. 181-192.

Tolson ND, Charlton KM, Stewart RB, Campbell JB, Wiktor TJ. 1987. Immune response in skunks to a vaccinia virus recombinant expressing the rabies virus glycoprotein. Can J Vet Res 51:363-366.

Wallace RM, Gilbert A, Slate D, Chipman R, Singh A, Wedd C, Blanton JD. 2014. Right place, wrong species: A 20-year review of rabies virus cross species transmission among terrestrial mammals in the United States. PLoS One 9:e107539. 
World Organisation for Animal Health. 2016. 2.1.17 Rabies. In: Manual of diagnostic tests and vaccines for terrestrial animals. World Organisation for Animal Health, Paris, France, pp. 26.

Yarosh OK, Wandeler AI, Graham FL, Campbell JB, Prevec L. 1996. Human adenovirus type 5 vectors expressing rabies glycoprotein. Vaccine 14:12571264.

Submitted for publication 7 April 2017.

Accepted 1 September 2017. 